\title{
Antioxidant Defencive Response of Ray Florets Underuncutand Cut Conditions in Cosmos bipinnatus Sonata Pink Series
}

\author{
Goral Jani ${ }^{1}$, Archana Mankad ${ }^{2}$ \\ M. N. College, Station Road, Visnagar \\ Department of Botany, School of Sciences, Gujarat University, Ahmedabad-380009, Gujarat, India
}

\begin{abstract}
Various parameters for the study of antioxidant defensive response such as total phenols, activities of polyphenol oxidase, peroxidase, catalase and IAA oxidasewere studied from the petals (ray florets) of flowers of Cosmos bipinnatus Cav. Sonata Pink series under uncut (flowers that remain attached to the plant)and cut (post-harvest) conditions after a regular interval of 24 hours from the time flowers opened or harvested till the end of the petal life under corresponding conditions. The total phenol content undercut conditions was found to be more as compared to that under uncut conditions. The polyphenol activity under cut conditions was found to be less than the activity under uncut conditions which supports moreamount of total phenols under these conditions.The peroxidase and catalase activity under cut conditions showed increase during senescent stage. This increase is an indicative of increased production of Reactive Oxygen Species and the flower is trying to reduce oxidative damage as well as suggests removal of free radical production. The activity of IAA oxidase under cut conditions was always less as compared to the uncut conditions suggesting lower levels of IAA in uncut flowers which possibly lead to the production of ethylene. This suggests that the antioxidant defense of the flowers under cut conditions was better as compared to that of the flowers under uncut conditions and this is why the cut flowers managed to have more shelf life as compared to the flowers under uncut conditions.
\end{abstract}

Keywords: Cosmos bipinnatus, antioxidant response, ROS, free radical, post-harvest.

\section{Introduction}

Flowers, one of the beautiful structures of the mother nature, apart from being aesthetically important serves a special purpose of sexual reproduction for the perpetuation of Earth's most dominant group of plants. The aesthetic beauty and value is affected by the turgidity and freshness of the petals which is regulated by its cellular redox homeostatic condition. Any imbalance in this stable state may lead to the production of reactive oxygen species (ROS) which are known to damage the primary metabolites in the plants thereby making the flowers unacceptable. But the antioxidative scavenging systems in the petals defend them against the oxidative stress induced due to imbalance. Thus, in the present study, an attempt has been made to make a comparative study of the antioxidative response of ray florets of flowers of Cosmos bipinnatusSonata Series "Sonata Pink" under uncut (senescence) and cut (postharvest) conditions.

\section{Literature Survey}

Increase in respiration and enzymatic hydrolysis of cellular components are the two major biochemical and metabolic events occurring in senescing petals. The enzymic changes found during petal senescence are associated mainly with these two processes. Increase in peroxidases has been found in senescing petals of several plants [1], [2], [3], [4], [5]. The increased activity of peroxidases is apparently related to an increase in peroxides and free radicals, which react with cellular constituents [6] and are involved in promotion of senescence [7], [8] and possibly also in ethylene production [9]. [10] also reported that the POD enzymes are thought to scavenge toxic free radicals and thus reduces their inhibitory effect, however with the progress of ripening in Mango, the activities of the enzyme decreased which may be due to disintegration of enzyme proteins. A delay in the senescence of carnation flowers was demonstrated by treating them with free radical scavengers such as sodium benzoate [11].

[12] reported that the capacity of the antioxidative defense system is increased during the onset of senescence process but the imbalance between ROS production and antioxidant defenses ultimately led to oxidative damage. They also proposed that a decrease in the activity of a number of enzymes that normally prevent the build up of elevated free radical concentrations might partially account for the process. Polyphenol oxidase and peroxidase are the two major enzymes responsible for oxidation of phenolic compounds. Some studies have reported that these enzyme activities increase in response to different types of stresses, both biotic and abiotic [13]. [14] have also reported that an increase in the activity of these enzymes could be indicative of an increased production of ROS and a building up of a protective mechanism to reduce oxidative damage triggered by stress experienced by plants. [15] have also reported that the high activity of PPO might also participate in the enhanced tolerance to oxidative stress. As mentioned by [16] Catalase (CAT) and various peroxidases react with $\mathrm{H}_{2} \mathrm{O}_{2}$. $\mathrm{He}$ also reported that several enzymes such as SOD, CAT and POD are involved in the scavenging of the free radicals in plant systems. CAT scavenges $\mathrm{H}_{2} \mathrm{O}_{2}$ by breaking it down directly to form water and oxygen [17] and according to [18] an increase in its activity is related with increase in stress tolerance. [19], [20] reported increase in CAT activity during senescence in carnation petals. This indicates an increase in free radical production is counteracted, at least in part, by an increase in their degradation [21]. [22] also 


\section{International Journal of Science and Research (IJSR) \\ ISSN (Online): 2319-7064 \\ Index Copernicus Value (2013): 6.14 | Impact Factor (2014): 5.611}

proposed that free radicals and antioxidative enzymes are involved in the wilting of day lily petals. [23] reported that phenolic compounds serve in plant defense mechanisms to counteract reactive ROS in order to survive and prevent molecular damage and damage by microorganisms, insects and herbivores.

\section{Problem Definition}

It was observed that the post-harvest shelf life of flowers was more as compared to the acceptability of the flowers which stayed on the plant. Though the cut flowers were deprived of their natural source of nourishment, they appeared to be better than uncut flowers of the same age. Moreover, petal senescence is rarely studied in uncut flowers and is seldom compared to that in cut flowers. Thus, the comparative changes in the antioxidative response of the two is focused here.

\section{Methodology}

Biochemical estimations were done from $100 \mathrm{mg}$ fresh or dry petals of flowers from petals of each respective stage.

\section{Various Stages Identified}

Stages for Uncut Conditions :It was observed that the uncut flowers of Cosmosbipinnatusremained on the plant for 5 days with $6^{\text {th }}$ day as the senescent day at which the petals started abscising. Thus, 6 stages were defined as follows for the uncut flowers:

Stage 1: Flowers that had just opened (Day 1)

Stage 2: After 24 hours (Day 2)

Stage 3: After 48 hours (Day 3)

Stage 4: After 96 hours (Day 4)

Stage 5: After 120 hours (Day 5)
Stage 6 (Senescent stage): After 144 hours (Day 6)

Stages for Cut Conditions :In case of cut flowers of Cosmos, a shelf life of 7 days was observed. The flowers were completely unacceptable on $8^{\text {th }}$ day with the petals completely wilted and dried. Hence, in case of cut flowers 7 stages were defined as follows -

Stage 1: Day when the flowers were cut and placed in DW as holding solution (Day 1)

Stage 2: After 24 hours (Day 2)

Stage 3: After 48 hours (Day 3)

Stage 4: After 96 hours (Day 4)

Stage 5: After 120 hours (Day 5)

Stage 6: After 144 hours (Day 6)

Stage 7 (Senescent stage) : After 168 hours (Day 7)

Total phenols were estimated by the method of [24], Polyphenol oxidase by [25], Peroxidase by [26], IAA Oxidase by [27] and Catalase by [28].

\section{Results and Discussion}

\section{(a) Total Phenols}

Total Phenols amount had a decreasing trend in case of uncut flower petals. In case of cut flowers, the amount of total phenols showed a drop at stage 2 after which it was almost maintained and had a slight increase towards the senescent stage.

Phenols are known to be protective against stresses. Thus, their increased value towards the senescent stage in cut flowers suggests that the presence of more phenols in them helped them to sustain during the stressed condition.

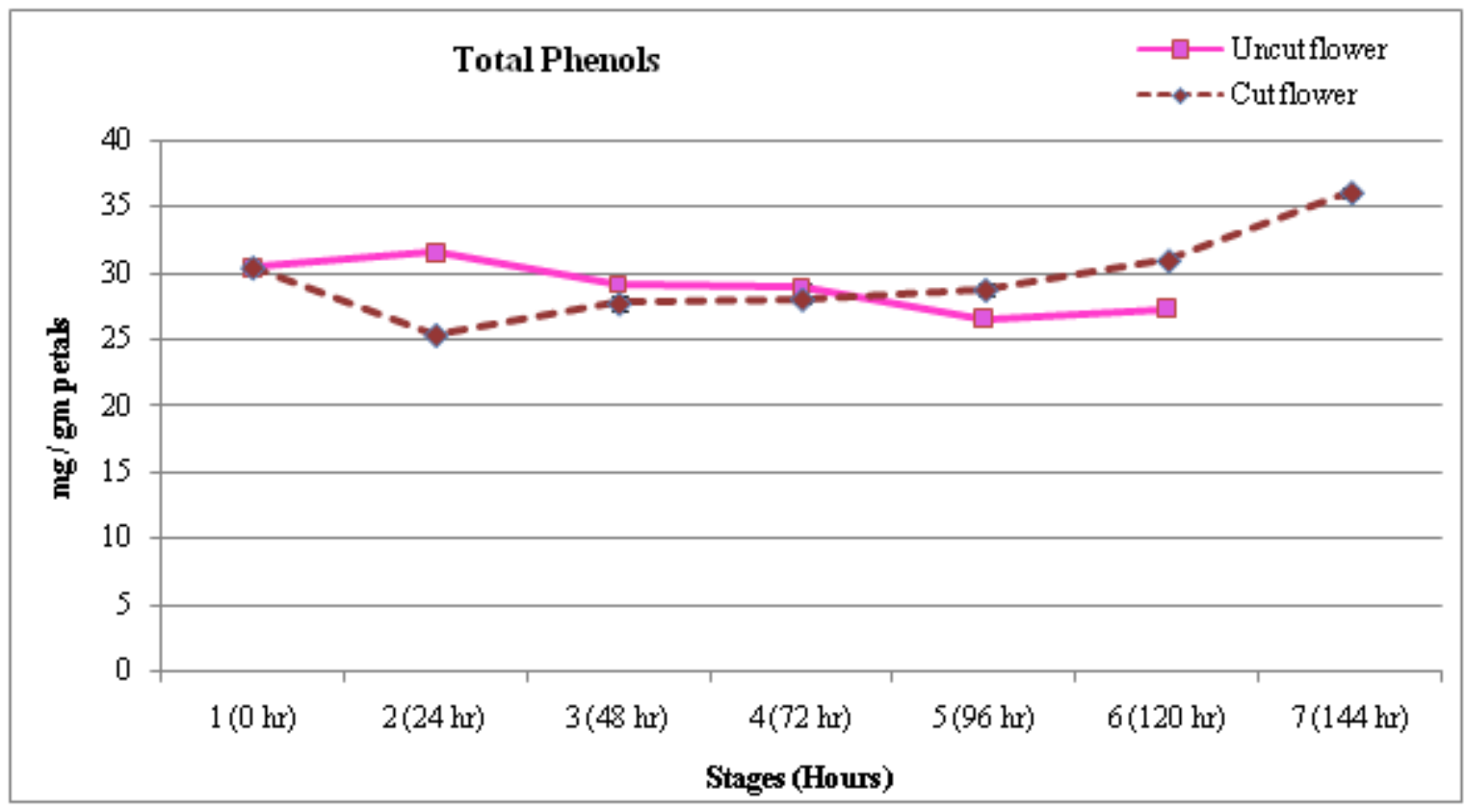

\section{(b) Polyphenol Oxidase}

PPO is an antioxidant enzyme responsible for the oxidation of phenolic compounds. It is known to be involved in scavenging ROS. PPO activity showed a slow gradual decrease towards the senescent stage in uncut flowers whereas in case of cut flowers the activity showed a remarkable increase towards the senescent stage. This can be the indication that there was more oxidation of ROS in case of cut flowers explaining longer shelf life in them as compared to uncut flowers. 


\section{International Journal of Science and Research (IJSR) \\ ISSN (Online): 2319-7064}

Index Copernicus Value (2013): 6.14 | Impact Factor (2014): 5.611

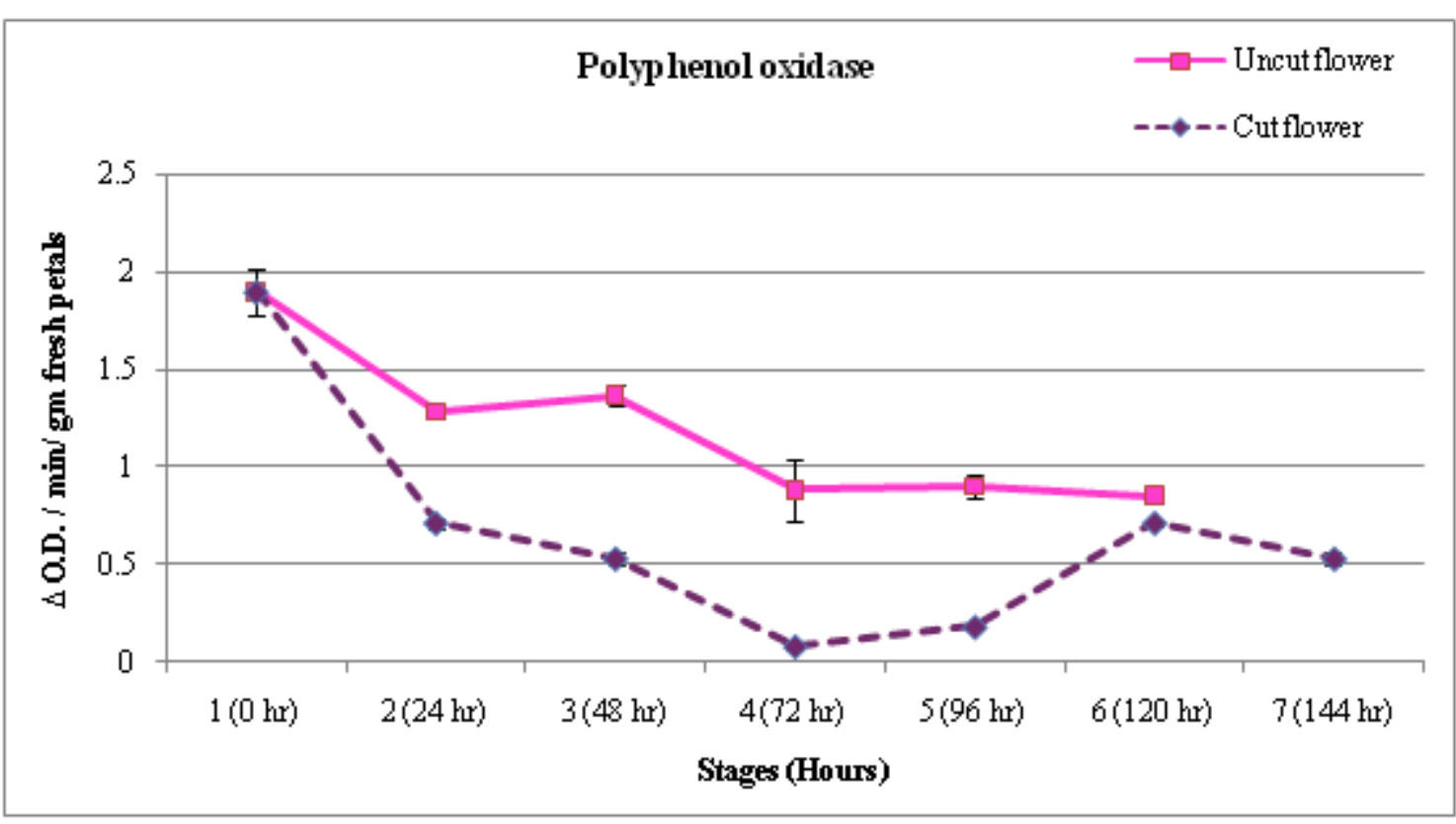

\section{(c) Peroxidase}

Peroxidase is known to deplete the pool of free radicals from accumulating to toxic levels during stress conditions. POD activity was found to decrease with the progressing stages in uncut flowers. This suggests that initially the activity of peroxidase enzyme did not allow the accumulation of free radicals which might have been produced due to the activity of intracellular generators like mitochondria. Thus, POD acted like a defense mechanism which protected the flower against the toxicity of the free radical accumulation. But with the progress of stages, the activity of enzyme decreased probably because with the advancement in stages the rate of respiration might have increased (as reported by many workers) which could have led to the increase in production of free radicals. These free radicals might have caused damage to the enzyme or enzyme proteins and hence reduction in activity is observed. Though the activity in both uncut and cut flowers were nearly similar, the activity was found to be more consistent in case of cut flowers which could have contributed towards prolonged shelf life.

Many workers have reported that in plant cells chloroplast, mitochondria and peroxisomes are intracellular generators of activated oxygen species such as $\mathrm{H}_{2} \mathrm{O}_{2}$, superoxides $\left(\mathrm{O}_{2}\right)$ radicals, hydroxyl radicals $\left(\mathrm{OH}^{-}\right)$and singlet oxygen $\left(\mathrm{O}_{2}{ }^{-}\right)$ [29] , [30]. The activated oxygen species are highly reactive and can cause damage to cell structure and function. Moreover, accumulation of free radicals may initiate senescence [31] , [32], [33].

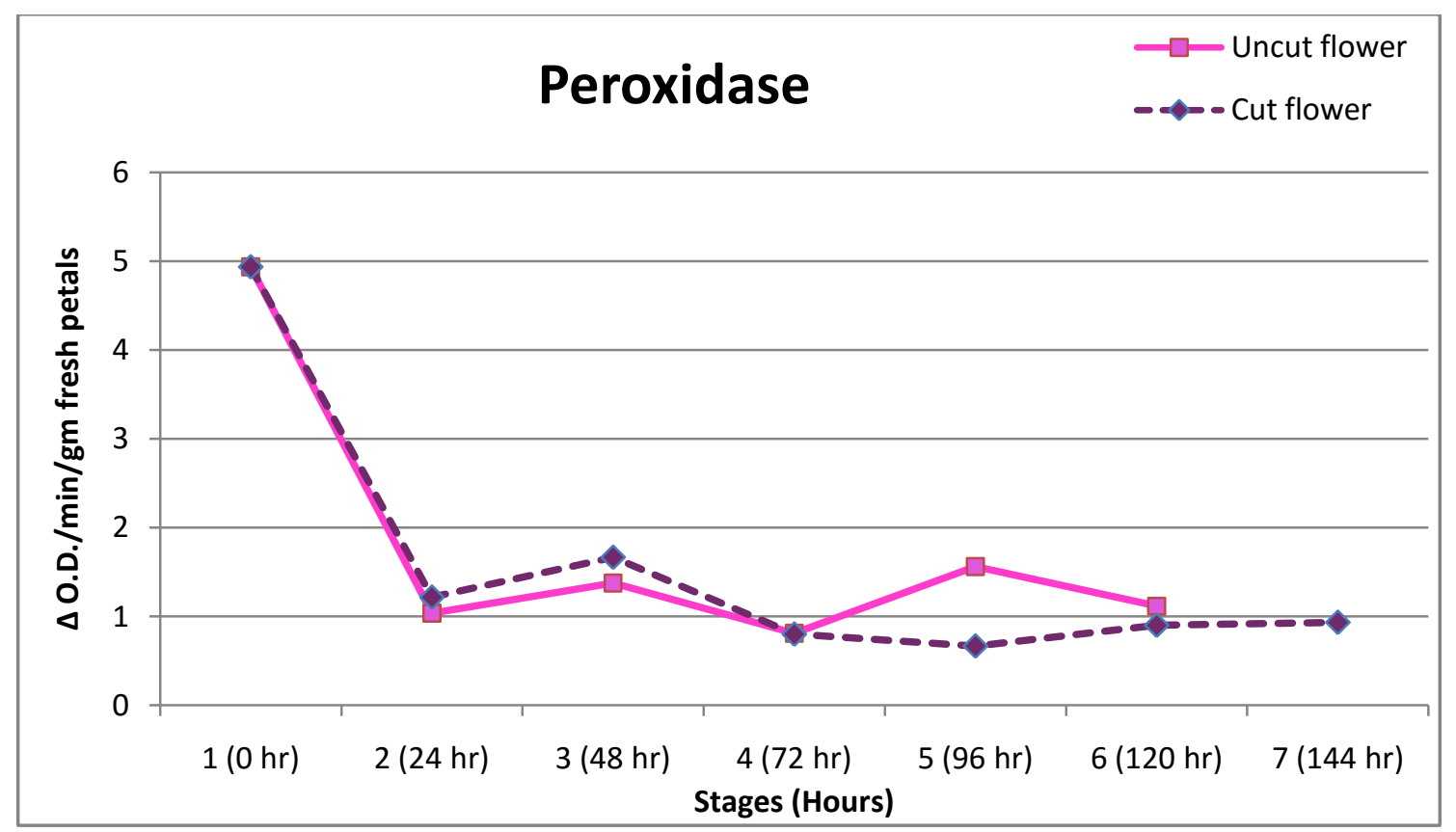




\section{International Journal of Science and Research (IJSR) \\ ISSN (Online): 2319-7064 \\ Index Copernicus Value (2013): 6.14 | Impact Factor (2014): 5.611}

\section{(d) Catalase}

CAT is one of the main free-radical scavenging enzymes which tend to increase during senescence. This might indicate that an increase in free radical production is counteracted, at least in part, by an increase in their degradation [34]. Catalase (CAT) react with $\mathrm{H}_{2} \mathrm{O}_{2}$ [16] by breaking it down directly to form water and oxygen [17], [15].

Uncut flowers showed a decreasing trend till stage 4 with a slight increase at stage 3 . After this, from stage 4 onwards a continuous sharp rise in the activity was observed. According to [18] increase in catalase activity is related with increase in stress tolerance. Thus, possibly the flowers were under some stress probably due to higher production of free radicals and/or ROS and increased activity suggests that it was trying to tolerate and defend against this stress.

Incase of cut flowers, the CAT activity started increasing slightly until stage 4 which was almost maintained at stage 5 and again had an increase till senescence period. This difference in the activity under the two conditions indicate that the flower petals under cut conditions were able to manage the accumulation of toxic compounds better as compared to flower petals under uncut conditions. This possibly was the reason of better longevity of cut flowers than the uncut flowers.

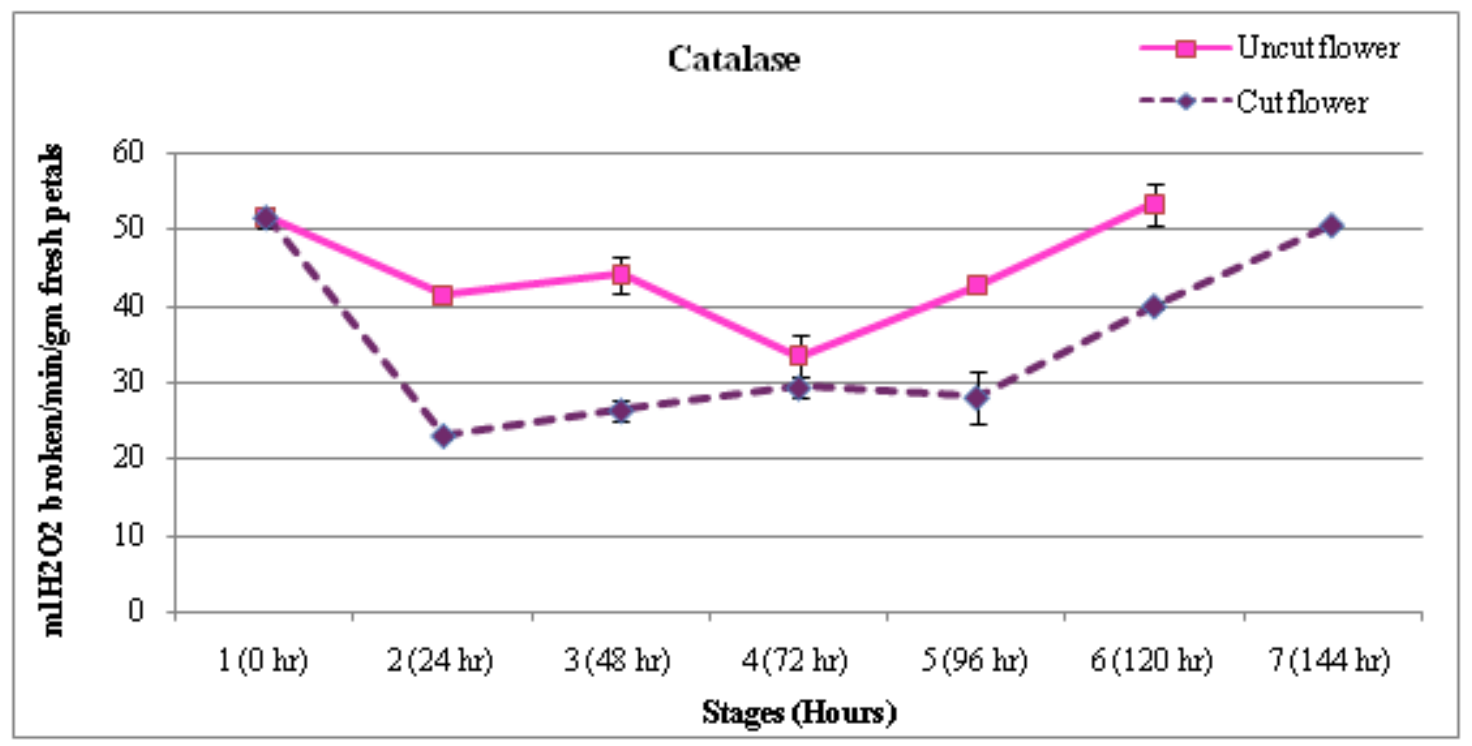

\section{(e) IAA Oxidase}

IAA Oxidase activity was found to be more in case of uncut flowers as compared to cut flowers. Since IAA oxidase is related with the degradation of IAA (auxin), decrease in the amount of auxin would trigger the senescence process in uncut flowers earlier. The decrease in auxin levels can be correlated with the promotion of ethylene production and thereby the cause of triggering the process of senescence.
[35] while working with carnation reported that IAA was found to stimulate ethylene production and consequently senescence and ethylene production was dependent on IAA concentration. [36] have also reported that low level of 2,4$\mathrm{D}$ to carnation promoted ethylene production and accelerated senescence while higher level delayed senescence.

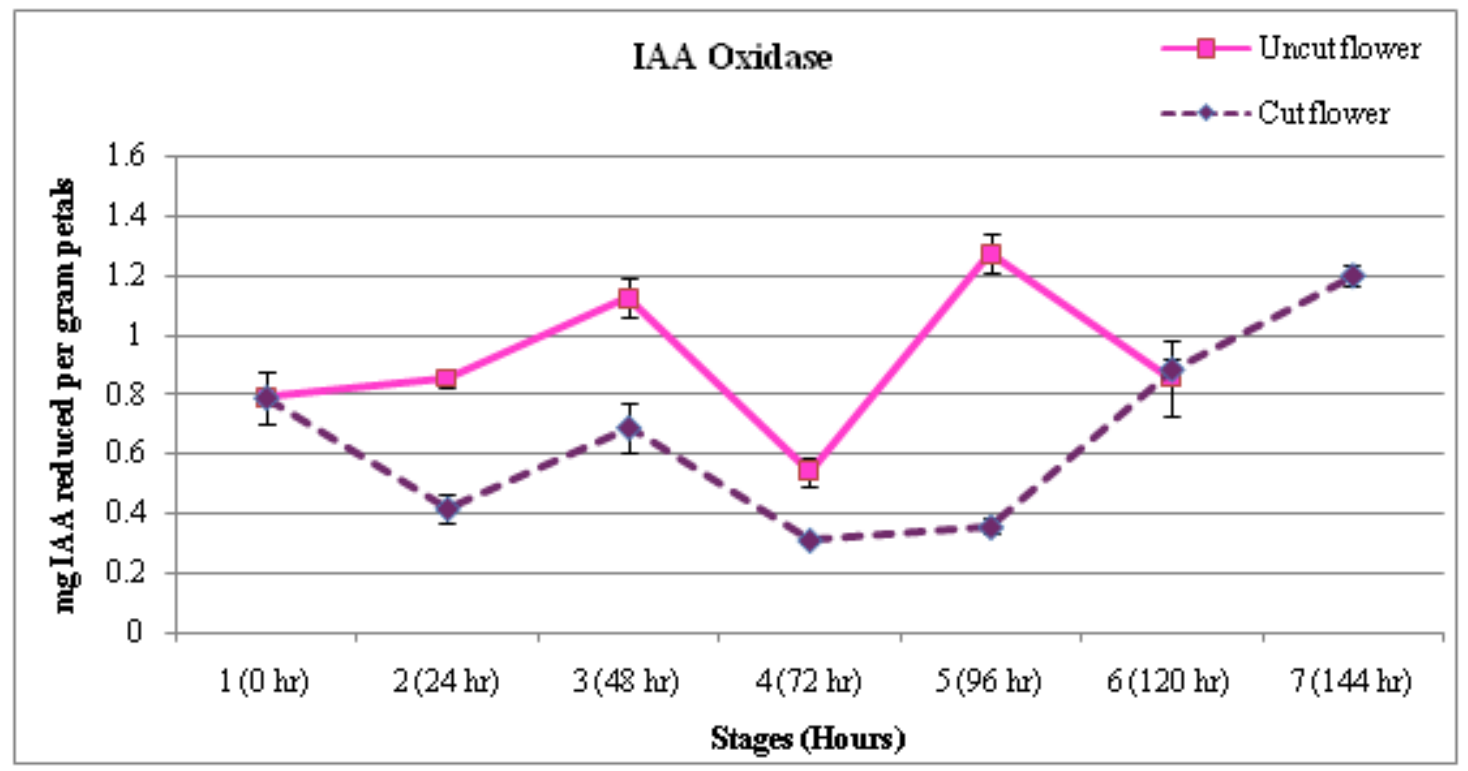




\section{International Journal of Science and Research (IJSR) \\ ISSN (Online): 2319-7064 \\ Index Copernicus Value (2013): 6.14 | Impact Factor (2014): 5.611}

\section{Conclusion}

In case of uncut flowers, stage 4 can be correlated with the act of pollination and it possibly acted as a trigger mechanism for senescence. ROS is possibly more produced after this stage. Hence, more activity of antioxidants (POD, PPO, CAT) was observed at the later stage. But, as the role of petals was achieved, the rescue mechanism (for the metabolites) was set on.

On the other hand, in case of cut flowers the point of degradation was pushed back as the flower overall tried to maintain the internal homeostatic condition, thereby having less oxidative stress and as a result there was less damage. This possibly is the reason for the enhancement in the shelf life of the cut flower as compared to the uncut flowers. Scarcity of nutrients could possibly be the cause of trigger of senescence in case of cut flowers.

\section{References}

[1] Panavas, T. and B. Rubinstein : Oxidative events during programmed cell death of day lily (Hemerocallis hybrid) petals. Plant Sci. 133 pp- 125-138, 1998.

[2] Bartoli, C. G.; M. Simontacchi, J. Guiamet, E. Montaldi and S. Puntarulo :Antioxidant enzymes and lipid peroxidation during aging of Chrysanthemum morifolium RAM petals Plant Sci. 104 pp- 161-168, 1995.

[3] Brendemeijer, G. M. M. : Peroxidase activities and peroxidase 's isoenzyme patterns during growth and senescence of the unpollinated style and corolla of tobacco plants. Acta Bot. Neerl.22 pp- 40-48, 1973.

[4] Carfantan, N. and J. Daussant : Preliminary study of tulip protein during senescence.Acta Hort., 41 pp- 3143,1975

[5] Trippi, V. S. and M. Tran ThanhVan :Changes in the pattern of some isoenzymes of the corolla after pollination in PhalaenopsisamabilisBlume. Plant Physiol. 48 pp- 506-508, 1971.

[6] Fridovich, I. : Superoxide dismutases, Annu. Rev. Biochem. 44 : 147-159, 1975.

[7] Brennan, T. and C. Frenkel : Involvement of hydrogen peroxide in the regulation of senescence in pear.Plant Physiol. 59 pp- 411-416, 1977.

[8] Mishra, S. D., B. K. Gaur, V. W. Bedekar and B. B. Singh:Isolation, identification and significance of free radicals in senescing leaves. Acta Bot. Indica4 : 131138, 1976.

[9] Beauchamp, C. and I. Fridovitch :A mechanism for the production of ethylene from methional. The generation of the hydroxyl radical by xanthine oxidase.J. Biol. Chem. 245 : 4641-4646, 1970.

[10]Reddy, Y. V. and G. C. Srivastava :Superoxide Dismutase and Peroxidase activities in ripening Mango (Mangiferaindica L.) fruits. Indian J. Plant Physiol. 8(2) : 115-119, 2003.

[11]Baker, J. E., C. Y. Wang, M. Lieberman and R. Hardenburg: Delay of senescence in carnations by a rhizobitoxine analog and sodium benzoate. HortScience.12 : 38-39, 1977.

[12] Chakrabarty, D., A. K. Verma and S. K. Datta : Oxidative stress and antioxidant activity as the basis of senescence in Hemerocallis (day lily) flowers. Journal of Horticulture and Forestry1(6) : 113-119, 2009.

[13] Rivero, R. M.; J. M. Ruiz, P. C. Garcia, L. R. LozezLefebre, E. Sanchez and L. Romero: Resistance to cold and heat stress : accumulation of phenolic compounds in tomato and watermelon plants. Plant Sci.160 : 315321, 2001.

[14] Scalet, M., R. Federice, M. C. Guido and F. Manes: Peroxidase activity and polyamine changes in response to ozone and stimulated acid rain in Aleppo pine needles. Environ. Exp. Bot.35 : 417-425, 1995.

[15] Agarwal, S. and V. Pandey: Stimulation of stressrelated antioxidative enzymes in combating oxidative stress in Cassia seedlings. Indian J. Plant Physiol. 8 (3) : 264-269, 2003

[16] Monk, L. S.; K. V. Fagerstedt and R. M. M. Crawford: Oxygen toxicity and superoxide dismutase as an antioxidant in physiological stress. Physiol. Plant76 : 456-459, 1989.

[17] Scandalios, J. G. : Oxygen stress and superoxide dismutases. Plant Physiol. 101 : 7-12, 1993.

[18] Kraus, E.; McKersie, B. D. and Fletcher, R. A. :Paclobutrazol induced tolerance of wheat leaves to paraquat may involve increased antioxidant enzyme activity. J. Plant Physiol. 145 : 570-576, 1995.

[19] Droillard, M. J., A. Paulinand J. C. Massot : Free radical production, catalase and superoxide dismutase activities and membrane integrity during senescence of petals of cut Carnations(Dianthus caryophyllus). Physio.Plant.71: 197-202, 1987.

[20]Droillard, M. J., D. Bureau and A. Paulin (1989) :Changes in activities of superoxides dismutase during aging of petals of cut Carnations(Dianthus caryophyllus). Physio.Plant.76: 149-154, 1989.

[21] Buchanan-Wollaston, V. (1997) :The molecular biology of leaf senescence.J. of Expt. Bot.48 : 181-199, 1997.

[22] Panavas, T. and B. Rubinstein : Oxidative events during programmed cell death of day lily (Hemerocallis hybrid) petals. Plant Sci.133 : 125-138, 1998.

[23] Vaya, J., Belinky, P. A. and Aviram M (1997) : Antioxidant constituents from licorice roots : Isolation, structure elucidation and antioxidative capacity toward LDL oxidation. Free Radical Biol. Med., 23(2) : 302313, 1997.

[24] Bray, H. G. and W. V. T. Thorpe :Analysis of phenolic compounds of interest in metabolism, Meth.Biochem.Anal.1 : 27-52, 1954.

[25]Kar, M. and D. Mishra:Catalase, peroxidase and polyphenol oxidase activities during leaf senescence. Plant Physiol.57 : 315-319, 1976.

[26] George, P. :Intermediate compound formation with peroxidases and stronf oxidizing agents. J. Biol. Chem. $201:$ 413, 1953.

[27] Mahadevan, S. :Enzymes involved in the synthesis and breakdown of IAA. In : Modern Methods of Plant Physiology. 7 : 233-259. M. F. Linskons, B. D. Sanwar and M. V. Tracey (Eds.), 1964.

[28] Chance, B. and A. C. Maehly :Assay of catalase and peroxidase. In : Methods of enzymology. S. P. Colowick and N. O. Kaplan (Eds.), Academic press, New York. 76(2) , $4: 777,1955$.

[29] del Rio, L. A. and R. P. Donaldson (1995) :Production of superoxide radicals in glyoxysomal membrane from 


\section{International Journal of Science and Research (IJSR) \\ ISSN (Online): 2319-7064}

Index Copernicus Value (2013): 6.14 | Impact Factor (2014): 5.611

castor bean endosperm.J. Plant Physiol.146 : 283-287, 1995.

[30] Lopez-Huertas, E., L. M. Sandalio, M. Gomez and L. A. del Rio:,Superoxide radical generation in paroxysmal membrane : Evidence for the participation of the $18 \mathrm{Kda}$ integral membrane polypeptide ${ }^{e c}$. Free Radical Res. 26 : 497-506, 1997.

[31]Elstner, E. F.:Oxygen activation and oxygen toxicityAnn. Rev. Physiol. 33 : 73-96, 1982.

[32] Elstner, E. F. : „Mechanism of oxygen activation in different compartments of plant cells ${ }^{\text {ee }}$ In : Activated Oxygen Species, Oxidative Stress and Plant Metabolism (Eds.) Pell, E. J. and Steffen, K. L. Rockville, MD, U.S.A. : Am. Soc. Plant Physiologists, pp : 13-25, 1991.

[33] Halliwell, B. and J. M. C. Gutterridge : Free Radicals in Biology and Medicine. Second edn. Clarendon, Oxford, U. K. : Oxford Press, 1989.

[34] Buchanan-Wollaston, V. :The molecular biology of leaf senescence.J. of Expt. Bot.48 : 181-199, 1997.

[35] Wulster, G., Sacalis, J. and Janes, H. :The effect of inhibitions of protein synthesis on ethylene induced sesnescence in isolated carnation petals. J. Am. Soc. Hort. Sci.107 : 112-115, 1982.

[36] Sacalis, J. N. and R. Nichols :Effect of 2,4 -D uptake on petal senescence in cut carnation flowers. Hort. Sci.15 : 499-500, 1980.

\section{Author Profile}

Goral Janiis working as Assistant Professor in Department of Biology, M. N. College, Visnagar. She holds a teaching experience of 7 years and a research experience of about 10 years.

ArchanaMankadis working as the Head of the Department, Department of Botany, Gujarat University, Ahmedabad. She has guided 39 students and possess a research experience of about 28 years. 